\title{
Quantifying cryptic Symbiodinium diversity within Orbicella faveolata and Orbicella franksi at the Flower Garden Banks, Gulf of Mexico
}

The genetic composition of the resident Symbiodinium endosymbionts can strongly modulate the physiological performance of reef-building corals. Here, we used quantitative metabarcoding to investigate Symbiodinium genetic diversity in two species of mountainous star corals, Orbicella franksi and Orbicella faveolata, from two reefs separated by 19 kilometers of deep water. We aimed to determine if the frequency of different symbiont genotypes varied with respect to coral host species or geographic location. Our results demonstrate that across the two reefs both coral species contained seven haplotypes of Symbiodinium, all identifiable as clade B and most closely related to type B1. Five of these haplotypes have not been previously described and may be endemic to the Flower Garden Banks. No significant differences in symbiont composition were detected between the two coral species. However, significant quantitative differences were detected between the east and west banks for three background haplotypes comprising $0.1 \%-10 \%$ of the total. The quantitative metabarcoding approach described here can help to sensitively characterize cryptic genetic diversity of Symbiodinium and potentially contribute to the understanding of physiological variations among coral populations. 
1 Elizabeth A. Green ${ }^{1}$, Sarah W. Davies², Mikhail V. Matz², Mónica Medina ${ }^{3 *}$

2 1. Quantitative and Systems Biology, University of California, Merced, 5200 North Lake Road,

3 Merced, CA 95343, USA

4 2. Department of Integrative Biology, The University of Texas at Austin, 1 University Station

5 C0990, Austin, TX 78712, USA

6 3.* Department of Biology, Pennsylvania State University, 326 Mueller, University Park, PA

7 16801, USA, (814) 867-2958, monicamedina@psu.edu, Corresponding Author

\section{Introduction}


The symbiotic relationship between scleractinian corals and dinoflagellate algae in the genus Symbiodinium is well known, but there is still much to understand about the establishment and plasticity of this complex symbiosis. Knowledge of Symbiodinium taxonomic diversity has increased over the last two decades with advancing molecular genotyping techniques detecting novel genotypes within each of the nine recognized clades (Coffroth \& Santos 2005; Pochon \& Gates 2010). Some of these genotypes may impart different physiological benefits and evidence suggests that the genetic composition of the resident Symbiodinium population can strongly modulate fitness traits of the coral holobiont (Rowan et al. 1997; Sampayo et al. 2008; Voolstra et al. 2009).

Symbiodinium algae provide hosts with photosynthetic products critical for metabolic processes and calcification (Muscatine \& Cernichiari 1969; Muscatine et al. 1984; Trench 1987). A malfunctioning symbiosis leads to a bleaching event where the algal cells are expelled resulting in a white coloration of the coral (Glynn 1993; Hoegh-Guldberg 1999; Hoegh-Guldberg \& Smith 1989). The coral host may or may not recover from a bleaching event (Lang et al. 1992; Marshall \& Baird 2000), which depends on the severity and duration of stress but also can strongly depend on the presence of minor frequency Symbiodinium taxa (i.e. genotypes) in the holobiont prior to bleaching (Berkelmans \& van Oppen 2006; Jones et al. 2008; LaJeunesse et al. 2010a; Putnam et al. 2012). Understanding the flexibility of symbiosis between corals capable of housing a mixed infection (Douglas 1998; LaJeunesse et al. 2003) versus corals with supposedly strict specificity for one symbiont type (Diekmann 2002; Sampayo et al. 2007) will lead to a better understanding of the ability of corals to survive environmental stressors.

Understanding the factors driving endosymbiont distributions is critical in the assessment of coral reef resilience. Different Symbiodinium species have shown varying photosynthetic efficiency and responses to the amount of light exposure suggesting coral host physiology is at least partially dependent on symbiotic interactions (DeSalvo et al. 2010; Fitt \& Warner 1995; Warner et al. 1996). While the importance of the functional implications of genetic diversity within Symbiodinium clades and subclades and how their presence correlates with environment has been frequently pointed out in literature (Baker 2003; Knowlton \& Rohwer 2003), only recently is evidence starting to emerge about broad physiological adaptations within Symbiodinium clades (Frade et al. 2008; Van Oppen et al. 2001; Warner et al. 2006). Some general attributes for Symbiodinium genotypes belonging to clades A-C have been proposed. Some members of clades A and B have been more commonly found in high irradiance environments ( 


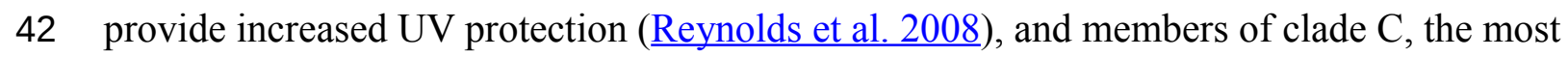

43 diverse Symbiodinium lineage are thought to enhance host calcification rates (Cantin et al. 2009;

44 LaJeunesse 2005). However initial efforts to assign distinct physiological roles of Symbiodinium

45 genotypes have been limited by the resolution of the few available genetic markers and methods.

46 Many of the early clade level generalizations were based on coarse resolution genotyping

47 techniques thereby missing the potential physiological contributions of undetected low frequency Symbiodinium taxa.

49 It is therefore essential to develop procedures to analyze Symbiodinium at the subclade

50 level in a consistent and quantitative manner. Advances in molecular techniques utilized for

51 Symbiodinium genotyping over the past two decades have resulted in important insights, such as

52 mixed Symbiodinium populations in various coral species and novel symbiont genotypes that

53 previously went undetected (Baird et al. 2007; Baker \& Romanski 2007; Fay \& Weber 2012;

54 LaJeunesse 2002; Rowan et al. 1997; Thornhill et al. 2014). However, some of the

55 electrophoresis-based methods do not guarantee detection of novel, often low-frequency

56 genotypes, and only confidently detect strains comprising $10 \%$ or higher of the total

57 Symbiodinium population (LaJeunesse et al. 2008; Thornhill et al. 2006). Use of next-generation

58 sequencing (NGS) platforms is now gaining popularity as a cost effective, high throughput

59 method capable of discovering and quantifying low frequency strains of Symbiodinium within

60 mixed symbiotic communities, with practical detection limits down to $0.1 \%$ (Kenkel et al. 2013;

61 Quigley et al. 2014). Quantitative investigation of low frequency Symbiodinium genotypes, with

62 potential different physiologies, in mixed communities can greatly enhance our understanding of

63 hidden diversity that could potentially play an important role in holobiont fitness (Jones \&

64 Berkelmans 2010; Mieog et al. 2009).

65 Here we introduce a universally applicable statistical framework to perform such

66 quantitative analysis, and apply it to investigate the Symbiodinium communities within two

67 species of the endangered Caribbean Orbicella annularis species complex (IUCN 2011),

68 formerly known as a member of the genus Montastraea (Budd et al. 2012). The

69 Orbicella annularis species have been previously shown to host mixed populations of

70 Symbiodinium (Rowan \& Knowlton 1995; Rowan et al. 1997). We used a metabarcoding

71 approach to study two Orbicella species -O.faveolata and O.franksi - at two locations within the

72 Flower Garden Banks National Marine Sanctuary (east and west bank), separated by $19 \mathrm{~km}$ of

73 deep water, to see whether the Symbiodinium community variation in these host species is

74 partitioned largely with respect to the host species or with respect to geographic location. 
75 Methods

76 Locations

77 The Flower Garden Banks (FGB) is a National Marine Sanctuary established in 1992 and 78 situated 185 kilometers off the coast of Texas $\left(27^{\circ} 54^{\prime} \mathrm{N}, 93^{\circ} 35^{\prime} \mathrm{W}\right.$ and $27^{\circ} 53^{\prime} \mathrm{N}, 93^{\circ} 49^{\prime} \mathrm{W}$ for 79 east and west localities, respectively) in the Gulf of Mexico (Fig. 1). The east and west banks are 80 separated by 19 kilometers. Flower Garden Banks are the most northern coral reefs in the Gulf of 81 Mexico making it an important location to understand limits of latitudinal distributions of coral 82 species ( $\underline{\text { Schmahl et al. 2008) }}$. Twenty-four shallow-water ( $<50$ meters) coral species reside at the 83 east and west FGB ( Schmahl et al. 2008). Compared to other Caribbean reefs, the FGB have 84 lower species diversity, but have much higher coral cover ranging between $50 \%$ and $70 \%$ (Precht 85 et al. 2005). In addition, the FGB is a relatively deep reef starting at 17 meters and extending 86 beyond 45 meters (Schmahl et al. 2008). Annual average temperatures range between $18^{\circ} \mathrm{C}$ and $30^{\circ} \mathrm{C}$ providing a unique opportunity to study corals exposed to their thermal minima ( $\underline{\text { Schmahl et }}$ al. 2008). The remote location of the FGB protects these reefs from most anthropogenic stressors; both land based and recreational.

\section{Coral Collections}

A total of $1971 \mathrm{~cm} \times 1 \mathrm{~cm}$ coral fragments were collected from the outer edge of Orbicella colonies at both the east and west FGB in August 2011 (O. faveolata, $\mathrm{n}=96)$ and August 2012 (O. franksi, $\mathrm{n}=101$ ) with approximately $\mathrm{n}=50$ per species per bank. Coral tissue was preserved in $96 \%$ ethanol and stored at room temperature. Sample depth ranged from 21 to 23 meters.

\section{Laboratory Procedures and Host Genotyping}

FGB holobiont DNA was isolated following the phenol-chloroform protocol described in Davies et al. (2013). One hundred ninety-three coral hosts were successfully amplified at nine microsatellite loci (Davies et al. 2013). STRUCTURE (version 2.3.4) output (q-score) (Falush et al. 2003; Falush et al. 2007; Hubisz et al. 2009; Pritchard et al. 2000) was used to identify nonhybrid coral colonies. Hybrids from the $O$. annularis species complex have been reported in literature (Budd \& Pandolfi 2004; Fukami et al. 2004; Szmant et al. 1997). Only individuals with greater than $80 \%$ posterior probability of belonging to one of the two major STRUCTURE derived clusters were retained (73 samples of $O$. faveolata and 101 samples of $O$. franksi) (Foster et al. 2012). Sixty of these, fifteen colonies of $O$. faveolata and fifteen colonies of $O$. franksi from both east and west FGB, were chosen for Symbiodinium ITS-2 genotyping. To look for genetic structure among coral populations between the two locations (east and west banks), an admixture model was run starting with a uniform alpha for degree of admixture, uncorrelated allele 
108 frequencies for five simulations, a burn-in of 300,000 steps and 106 Markov-Chain Monte Carlo

109 (MCMC) iterations. STRUCTURE results were then used as input to run STRUCTURE

110 HARVESTER to select the optimal number of clusters (K) (Earl \& vonHoldt 2012; Evanno et al.

111 2005). Using CLUMPP (Jakobsson \& Rosenberg 2007), output files from STRUCTURE

112 HARVESTER were used to combine the results of replicated runs by computing weighted

113 averages followed by plotting the results using DISTRUCT (

114 species differentiation, each species was analyzed separately in STRUCTURE applying the same

115 parameters for all analyses (Foster et al. 2012). An analysis of molecular variance (AMOVA) was

116 implemented in GenAlEx (version 6.5) to assess genetic differentiation by computing pairwise

$117 F_{S T}$ for species and sites (Peakall \& Smouse 2012).

118 Amplification of ITS-2 for 454 sequencing

119 ITS-2 was amplified in each of the sixty individual hosts and submitted for deep amplicon 120 sequencing in January 2013 using Symbiodinium specific ITS-2 primers, ITS-Dino-forward (5'-

121 GTGAATTGCAGAACTCCGTG-3') (Pochon et al. 2001) and its2rev2-reverse (5'-

122 CCTCCGCTTACTTATATGCTT-3') (Stat et al. 2009). The target amplicon was approximately

123300 base pairs long. Each $30 \mu \mathrm{L}$ PCR reaction contained $13.3 \mu \mathrm{L}$ of water, $3.0 \mu \mathrm{L} 10 \times$ ExTaq HS

124 buffer, $0.2 \mathrm{mM}$ dNTP, $0.75 \mathrm{U}$ ExTaq HS polymerase (Takara Biotechnology), 0.375 U Pfu

125 polymerase (Agilent Technologies), $0.2 \mu \mathrm{M}$ final primer concentration and $50 \mathrm{ng}$ of DNA

126 template (Kenkel et al. 2013). A DNA Engine Tetrad 2 Thermal Cycler (Bio-Rad, Hercules, CA,

127 USA) was used for all amplifications. The following PCR protocol was used: 20 cycles of $94^{\circ} \mathrm{C}$

128 for five minutes, $95^{\circ} \mathrm{C}$ for 40 seconds, $59^{\circ} \mathrm{C}$ for two minutes, $72^{\circ} \mathrm{C}$ for one minute and final

129 extensions of $72^{\circ} \mathrm{C}$ for five minutes. PCR product intensity of all individuals was determined on

130 one two percent gel-red stained agarose gel. Additional cycles were added to individuals to obtain

131 the same uniform band intensity (just above the visibility threshold on an agarose gel) and the

132 final cycle number was recorded. Individuals that had not amplified by 35 cycles were repeated

133 using a lower starting template $(20 \mathrm{ng} / \mu \mathrm{L})$ to reduce the inhibition by contaminants. All

134 individuals amplified by 34 cycles except one west FGB $O$. faveolata and one east FGB

135 O. faveolata which were removed from the analysis. PCR products were cleaned using GeneJET

136 PCR purification kits (Fermentas Life Sciences). Six individuals were randomly selected and run

137 on two percent agarose gel to ensure sufficient DNA quantities remained post clean-up.

138 New $30 \mu \mathrm{L}$ PCR reactions were performed to incorporate A and B Rapid adaptors specific

139 for 454 GS FLX. The adaptors designs were: the reverse barcoded primer sequence (A-Rapid

140 primer+unique barcode+its2rev2 primer) and forward B-rapid primer (B-Rapid primer+ITS- 
141 Dino) (Fig. S1). A unique barcode was assigned to each amplified coral host individual $(\mathrm{n}=58)$.

142 Each reaction contained $50 \mathrm{ng}$ of cleaned PCR product, $17.6 \mu \mathrm{L}$ water, $0.2 \mathrm{mM} \mathrm{dNTP}, 3 \mu \mathrm{L} 10 x$

143 ExTaq HS buffer, 0.75 U ExTaq HS polymerase (Takara Biotechnology), 0.375 U Pfu polymerase

144 (Agilent Technologies), 50 ng of PCR product, $0.33 \mu \mathrm{M}$ of 454 B- Rapid ITS2-forward (5'-

145 CCTATCCCCTGTGTGCCTTGAGAGACGHC+GTGAATTGCAGAACTCCGTG-3’)

146 and $0.33 \mu \mathrm{M}$ of 454 A-Rapid ITS2 adaptor with unique barcode (5'-

147 CCATCTCATCCCTGCGTGTCTCCGACGACT+TGTAGCGC+CCTCCGCTTACTTATATGC

148 TT-3', example barcode sequence is shown in bold) (Kenkel et al. 2013). PCR was performed on

149 a DNA Engine Tetrad 2 Thermal Cycler (Bio-Rad, Hercules,CA,USA) under the following

150 conditions: $95^{\circ} \mathrm{C}$ for five minutes, four cycles of $95^{\circ} \mathrm{C}$ for 30 seconds, $59^{\circ} \mathrm{C}$ for 30 seconds, $72^{\circ} \mathrm{C}$

151 for one minute followed by incubation at $72^{\circ} \mathrm{C}$ for five minutes. Samples were verified on one

152 two percent agarose gel and pooled based on band intensity. Pools were ethanol precipitated.

153 Three to five micrograms of the cleaned product was run on a one percent SYBR Green

154 (Invitrogen) stained gel. The target band was excised using a blue-light box and soaked in $25 \mu \mathrm{L}$

155 of milli-Q water overnight at $4^{\circ} \mathrm{C}$. The supernatant was submitted and sequenced at the

156 University of Texas-Austin Genome Sequencing and Analysis Facility (GSAF) aiming to obtain

157 two thousand reads per sample.

158 Bioinformatic pipeline to obtain read count data

159 We provide a detailed bioinformatics walkthrough (Data S1). This and the updated

160 versions of the pipeline will be hosted on Matz lab Methods web page

161 (http://www.bio.utxas.edu/research/matz_lab/matzlab/Methods.html). Briefly, the pipeline relies

162 on three widely used software packages - fastx_toolkit (http://hannonlab.cshl.edu/fastx_toolkit/),

163 usearch (Edgar 2010) and SHRiMP2 (David et al. 2011) along with additional custom Perl scripts

164 to streamline processing of multiple read files. The pipeline can be run on any Linux, UNIX or

165 Mac OS-X computer. It includes four steps: (i) quality and length filtering of reads, (ii)

166 identifying haplotypes (or operational taxonomic units, OTUs), (iii) mapping the reads to the

167 newly assembled haplotype database, and (iv) deriving counts of unambiguous matches to each

168 haplotype within each sample. The pipeline is suitable for fasta or fastq formatted read files,

169 providing maximum versatility for use with the currently dominant NGS technologies. The OTUs

170 were used as queries for BLASTn (Altschul et al. 1990) and were aligned between each other

171 using Clustal Omega online server (version 1.2.0) (Goujon et al. 2010; McWilliam et al. 2013;

172 Sievers et al. 2011). Alignments were examined and manually edited using SeaView (version

173 4.4.2) (Gouy et al. 2010). The term 'genotype' will hereafter be used to reference previously 
174 published Symbiodinium clade types where the term 'haplotype' will reference the Symbiodinium

175 sequences represented in our collected dataset.

176 Model-based Analysis: Theory and Implementation

177 The OTU counts analysis follows the methodology described earlier (Matz et al. 2013),

178 implementing a Poisson-lognormal generalized linear mixed model to jointly infer parameters of

179 interest such as OTU-specific abundance changes in response to fixed factors as well as nuisance 180 parameters such as variation attributable to the random differences in sequencing depth among 181 samples. Incorporation of the Poisson component into the model makes it possible to adequately 182 analyze sparsely represented haplotypes that might be missing from many samples due to 183 undersampling rather than true absence.

184 Let $y_{o i j k}$ be the count for OTU $o$ under condition $i$, group $j$, sample $k$. The model assumes 185 that this count arises from a poisson-lognormal distribution:

$$
y_{o i j k} \sim P L N\left(\lambda_{o i j k}, \sigma_{o}^{2}\right)
$$

187

where PLN $(\mathrm{m}, \mathrm{v})$ denotes the Poisson-lognormal distribution with rate parameter $\mathrm{m}$ and log-

variance v. In our model, the log-variance is OTU-specific, and the rate term involves

189 regressions on both fixed and random effects.

$$
\psi_{\text {oijk }}=\log \left(\lambda_{\text {oijk }}\right)
$$

190 The model for log-rate term takes the form

$$
\begin{aligned}
& \psi_{o i j k}=S_{i j k}+I_{o}+B_{o i}+c_{k}+a_{o j} ; \\
& S_{i j k}=I^{s}+B_{i}^{s}+c_{k}+a_{j}^{s} .
\end{aligned}
$$

192 where $I_{o}$ represents an OTU-specific intercept, $B_{o i}$ is the fixed effect of condition $i$ on OTU $o$,. 193 (examples of condition being host species, location, or treatment), $c_{k}$ is a random effect meant to 194 capture the deviation in sequencing coverage in sample $k$, and $a_{o j}$ is the OTU-specific random 195 effect associated with the $j$ th level of some grouping variable (tank, block, or plot) and/or 196 individual if the design involved repeated measures. The $c_{k}$ and $a_{o j}$ are random effects modeled as 197 samples from Gaussian distributions; in case of $c_{k}$ it is the same distribution for all OTUs and in 198 case of $a_{o j}$ the distributions have OTU-specific variances. Both $B_{o i}$ and $a_{o j}$ terms represent design 199 matrices that can potentially include multiple factors as well as their interactions, or none at all. 200 The model in (2) is different from the one described in (Matz et al. 2013) in two minor 
201 aspects. First, it does not include the secondary error term, the OTU-specific effect of sample,

202 which would be hard to estimate without technical replicates (rare in metabarcoding); the

203 variance that would be attributable to this term is absorbed within the haplotype-specific residual $\sigma_{o}^{2}$

204 error term one level up in the model hierarchy (equation [1]). Another difference is the term

$205 S_{i j k}$ that describes the behavior of an artificial OTU with counts equal to the sum of all counts in a 206 sample. This "sum-OTU" is modeled together with all other OTUs, decomposing its variance into 207 its own intercept, fixed and random components (bottom row in [2]). Its special role in the model 208 (2) is that, after the model is fitted, the fixed OTU-specific effects $\left(B_{i h}\right)$ are being expressed 209 relative to the ones for the sum-OTU, which controls for possible systematic biases in coverage 210 across experimental conditions. It also makes it possible to express the inferred OTU abundances 211 as proportions of total, which is natural in metabarcoding.

The model is fitted to the data using a Bayesian Markov chain Monte Carlo (MCMC) 213 procedure utilizing non-informative over-dispersed priors for fixed effects, non-informative 214 inverse-Wishart priors (variance $\mathrm{V}=1$, degree of belief nu=0) for variance components $c_{k}$ and $a_{O J}$ 215 and the weakly informative inverse-Wishart prior $(\mathrm{V}=1$ and nu equal number of OTUs minus

$$
\sigma_{o}^{2}
$$

216 0.998) for the residual haplotype-specific error (Hadfield 2010). This formulation results in 217 well-mixed MCMC chains and the ability to handle up to about 200 OTUs on a personal 218 computer. The OTUs that are so sparsely represented that no reliable parameter estimates could 219 be obtained for them are detected based on high autocorrelation among sampled values and are 220 discarded from further analysis.

The statistical approach described above has been implemented in a user-friendly $\mathrm{R}$ package (MCMC.OTU) ( $\underline{\mathrm{R} \text { Developmental Core Team 2013 }}$ ). The official releases of the package are available from the Comprehensive R Archive Network (CRAN, http://cran.r-project.org/),

224 while the beta-versions and the walkthrough script based on the data from this paper are available 225 from Matz lab Methods web page

226 (http://www.bio.utexas.edu/research/matz_lab/matzlab/Methods.html).

227 In addition to the model-fitting function, the package MCMC.OTU includes functions for data 228 reformatting, selecting quantifiable OTUs based on proportion of global count, identifying OTUs 229 for which the model generated reliable parameter estimates and for converting raw counts into $230 \log$-transformed normalized data for principal component analysis and studies of among-OTU 
231 correlations (this transformation is described in the next section). MCMC.OTU package also

232 includes functions to calculate statistical significance for all possible pairwise comparisons and to

233 plot results. The package includes extensive documentation and examples, and is designed to

234 make the analysis accessible to the novice $\mathrm{R}$ user.

235

236

237

238

239

240

241

242

243

244

245

246

247

248

249

250

251

252

253

254

255

256

257

258

259

260

261

\section{Statistical Analysis: Orbicella Data}

The R script (with detailed comments) that was used to analyze Orbicella data is provided (Data S2). Briefly, the analysis involved four steps. First, outlier samples and OTUs are discarded. The criterion for discarding samples was the total log-counts being less by $\geq 2.5$ standard deviations than the mean across all samples; this resulted in discarding of a single sample of $O$. faveolata from the east bank. The OTUs were deemed quantifiable if they comprised at least $0.1 \%$ of global sum of counts, as per (Quigley et al. 2014). Second, the data are reformatted and the model is fitted; in this case the model included fixed effects of host species (O. faveolata or $O$. franksi), bank (east or west) and their interaction. Third, pairwise differences between all combinations of fixed effects are calculated based on their sampled posterior distributions, their statistical significances are calculated as described in (Matz et al. $\underline{2013}$ ) and adjusted for multiple testing using false discovery rate (FDR) correction (Benjamini \& Hochberg 1995). Fourth, the results are visualized as trellis plots.

For principal components analysis, all OTUs detected in greater than $10 \%$ of all samples were retained. The counts data were normalized by multiplying them by the sample size factor, which was computed as the ratio of the sum of counts in the sample to the mean sum of counts across samples, and $\log _{10}$-transformed using a "started log" method, in which the zero counts are replaced prior to log-transforming by a certain positive value (in this case 0.1 ). The MCMC.OTU package also implements the "log-linear hybrid" transformation (ocke \& Durbin 2003), which in downstream analyses gives very similar results to the ones obtained with the "started log" transform. The transformed data were subjected to principal components analysis using $\mathrm{R}$ (package 'vegan' Oksanen et al. 2013). The log-transformed normalized data in which the original zero count datapoints were left undefined were used to analyze pairwise correlations between haplotype abundance across samples with the assumption that OTUs representing the same genome (paralogs) are likely to show positive correlation, whereas negative correlation between two OTUs indicates that they represent different genomes (Kenkel et al. 2013).

\section{Analysis of structural conservation}



sequences from the ITS-2 database (http://its2.bioapps.biozentrum.uni-wuerzburg.de/) and

264 trimmed to be of equal length. The pooled dataset of the identified 19 B1 ITS-2 sequences was

265 then used to predict the structure for the trimmed seven B1 haplotypes using the 'model' tool

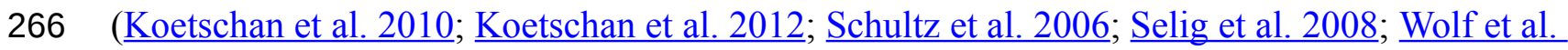

267 2005). The seven OTUs were aligned with the B1 model sequences used to predict secondary

268 structure using the 'sequence and structure' tool. The resulting aligned fasta file of sequences

269 with structure (Data S3) was opened in 4SALE to compare secondary structures looking for the

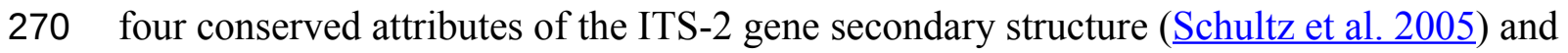

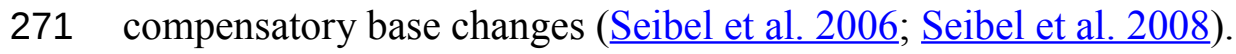

\section{Results}

273 Host genetics

STRUCTURE analysis detected genetic differences between the two coral species, but no divergence between locations for either of them (Fig. 2). Output files from STRUCTURE HARVESTER showed a delta $\mathrm{K}$ of two for all analyses except the independent analysis of Orbicella faveolata $(\mathrm{n}=73)$ which showed a delta K of three (Fig. S2). This result was verified by AMOVA analysis (Table 1). AMOVA results comparing $F_{\mathrm{ST}}$ between sites showed no significant genetic differentiation in Orbicella franksi (Table 1). Orbicella faveolata showed small, but significant $F_{\text {ST }}(p<0.02)$ between banks (Table 1), which was also reflected on the STRUCTURE plot (Fig. 2). There was a much clearer genetic differentiation between species (Fig. 2) with a significant $F_{\text {ST }}$ of 0.07 (Table 1). Symbiodinium metabarcoding summary

ITS-2 sequencing yielded 170,344 raw reads for 58 individuals, averaging 2,937 reads per individual (Table 2). After removing all reads shorter than 290bp, 122,867 reads representing 20,260 unique sequences remained. The clustering was performed at the $97 \%$ similarity level and resulted in 153 OTUs. The relatively high clustering threshold was chosen to maximize the power to detect low-divergence haplotypes, since in Symbiodinium even a few bases of difference in ITS-2 sequence could delineate ecologically distinct strains (e.g. LaJeunesse et al. 2004; LaJeunesse et al. 2003). All filtered reads were unambiguously mapped against this OTU

291 collection. The sum of unambiguous match counts per sample ranged from 256 to 5,394, with 292 median at 1,884 and $25 \%$ and $75 \%$ quartiles at 1,316 and 2,597, respectively. The sample with 293256 counts was subsequently discarded, leaving 864 as the next lowest sum of counts per sample. 
Of the 153 OTUs identified, ten were deemed amenable to quantitative analysis since

296

297

298

299

300

301

302

303

304

305

306

307

308

309

310

311

312

313

314

315

316

317

318

319

320

321

322

323

324

325

326

each of them exceeded $0.1 \%$ of the total counts (Quigley et al. 2014), but for only seven of them reliable parameter estimates could be obtained since the other three were too sparse among samples (found in eight or less samples out of 57). These seven OTUs, hereafter referred to as haplotypes, were analyzed further. Haplotype II was by far the most dominant accounting for $90.06 \%$ of all reads mapped across all individuals (Fig. 3). Poisson-lognormal generalized linear mixed model analysis revealed that haplotype IV was significantly (FDR $<0.026)$ diminished at the west bank in both species, haplotype VI was diminished in O. faveolata at the east bank $(\mathrm{FDR}=0.001)$, and haplotype VII was elevated in the west bank in both species $(\mathrm{FDR}<0.022)$ (Fig. 4 and Table S1).

\section{Sequence similarities of the detected haplotypes}

All seven haplotypes best matched Symbiodinium clade B type B1 (JN 558059.1) (Pochon et al. 2012), recently identified as Symbiodinium minutum (AF 333511.1) (LaJeunesse et al. 2012). After end-trimming to equalize length, haplotypes I and II matched B1 (JN 558059.1, AF 333511.1) (LaJeunesse et al. 2012; Pochon et al. 2012) with 100\% identity, whereas the remaining five haplotypes did not find an exact match in the database (Data S1 and Fig. S3, (Gouy et al. 2010)). Haplotype III differs from B1 by a 13 base pair deletion. Haplotype IV differs from B1 (JN 558059.1, AF 333511.1) (LaJeunesse et al. 2012; Pochon et al. 2012) by a ten base pair insertion. Haplotype V differs from B1 (JN 558059.1, AF 333511.1) (LaJeunesse et al. 2012; Pochon et al. 2012) by nine different single nucleotide insertions. Haplotype VI differs from B1 (JN 558059.1, AF 333511.1) (LaJeunesse et al. 2012; Pochon et al. 2012) by a nine base pair deletion and thymine insertion at position 156. Haplotype VII differs from B1 (JN 558059.1, AF 333511.1) (LaJeunesse et al. 2012; Pochon et al. 2012) by an eleven base pair deletion. These indels do not occur in homopolymer regions and are unlikely to be the results of 454 sequencing error (Margulies et al. 2005).

We additionally used NCBI nBLAST to identify the top database match for all 153 OTUs. The quantitative analysis of these OTUs was not possible due to their extremely sparse representation among our samples. Moreover, some of these rare OTUs were obvious contaminants. We detected 130 top hits with B1s, one B19a, three B3, one B2, one C90, one C91, one D1, one D2, one F5.2b, two G6, one G, one host contamination (Orbicella franksi) and several ITS-2 sequences for free-living dinoflagellates species.

Potential paralogous copies of novel Symbiodinium haplotypes detected 
328 haplotypes might be paralogous loci from the same genome (positive correlation) or not (negative 329 correlation) (Kenkel et al. 2013). Of the seven quantifiable haplotypes only III and V showed a 330 significant positive correlation $(\mathrm{p}=0.016)$. With the exception of these two haplotypes, correlation 331 analysis did not find evidence that any other of the haplotypes might be paralogous. Instead, it

332 confirmed genomic independence for some of them via negative correlations: haplotypes IV and 333 VI showed significant negative correlation with the major haplotype II ( $p<0.001$ and 0.023 , 334 respectively), and haplotype VII was negatively correlated with haplotype I ( $\mathrm{p}=0.0021)$ and VI $335(\mathrm{p}=0.032)$ (Fig. S4).

336 Pseudogene analysis

337 Three B1 model sequences with structure from the ITS-2 database were used to predict 338 the secondary structure for the seven haplotypes and top blast hit Symbiodinium B1 (JN 558059.1). Only 72.7\% of the third helix for the ITS-2 reference (GI 156466871) was found in the predicted secondary structure of haplotype III, while the fourth helix of haplotype V was only $85.7 \%$ complete compared to the reference structure (GI 156466870) (Table S2). The remaining haplotypes all had 100\% conservation in all four helices with the model B1 sequence

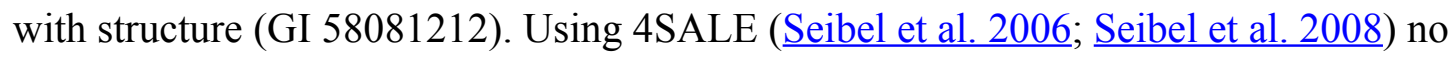
compensatory base changes (CBC) were detected when comparing haplotypes to their reference B1 sequence from the ITS-2 database. Visual comparisons using 4SALE structure viewer for haplotype III and V with their model B1 sequence showed high conservation across sites. However, given the reduced homology modeling results for haplotype III and V coupled with their positive correlation among samples, we predict that at least one of them (most likely haplotype III) is a paralog potentially representing a non-functional copy of the rRNA gene. Model-free approach

The first component (PC1) from the PCA explained 18.64\% of the variation and principle component two (PC2) explained $11.82 \%$ of the variation. Retaining the first six components meets Kaiser's criterion (Kaiser 1960), defined as all components with a standard deviation greater than one, and explain $62.67 \%$ of the variation. The samples were visibly partitioned with

\section{Discussion}

358 Host species delineation 
Nine recently developed microsatellite markers (Davies et al. 2013) were used for host

360

361

362

363

364

365

366

367

368

369

370

371

372

373

374

375

376

377

378

379

380

381

382

383

384

385

386

387

388

389

390

391

genotyping to distinguish the two host species, Orbicella faveolata and O. franksi, since these species have been shown to hybridize (Budd \& Pandolfi 2004; Fukami et al. 2004; Szmant et al. 1997). Species in the Orbicella annularis complex vary considerably morphologically, however genetic differences are not as pronounced making species identification in the

Orbicella annularis species complex challenging (Fukami et al. 2004). Microsatellite data were analyzed using STRUCTURE (Fig. 2) and AMOVA (Table 1) to ensure that the selected individuals were not recent hybrids.

\section{Detecting novel symbiont haplotypes}

Quigley et al. (2014) verified the detection sensitivity of the method used here for genotypes from clades A, C and D down to $0.1 \%$. In our study, five of the seven quantifiable haplotypes did not have an exact match in the NCBI sequence database and therefore were potentially novel. It remains to be seen whether these haplotypes are endemic to the FGB, since this metabarcoding approach has not yet been widely applied across the Caribbean. Another alternative (and a typical concern in metabarcoding) is that the detected rare haplotypes represent artifacts of amplification, sequencing or bioinformatics analysis, which is particularly probable in cases such as ours when OTUs are expected to be of low sequence diversity, necessitating the use of high sequence identity thresholds (97\%) during OTU inference. To deal with this issue to some degree, we chose a conservative approach while selecting haplotypes for further analysis. First, guided by the Quigley et al. (2014) results we required the candidate haplotypes to be present in appreciable counts ( $>0.1 \%$ of total, which amounts to about one hundred for our dataset). Second, our methodology implies that the haplotypes must be found across multiple samples to be amenable for quantification. These two criteria are expected to considerably lower the chance for the inferred haplotypes to be artifacts of sequencing or PCR. An additional assurance is provided by the fact that each of the minor haplotypes was discriminated by multiple small indels or a single large ( $\geq 10 \mathrm{bp}$ ) indel (Fig. S3), which are unlikely to happen as a result from sequencing or PCR errors. Further improvement of the reliability of detected OTUs can be obtained by sequencing independently prepared technical replicates, which we intend to explore in the future.

Another concern when using a multi-copy marker undergoing concerted evolution such as ITS-2 (Koch et al. 2003; Stat et al. 2011) is that some of the detected haplotypes could be paralogs or pseudogenes from the same genome (Thornhill et al. 2007) rather than true representative of unique symbiont strains. To address this issue, our method follows Kenkel et al. (2013) in exploring pairwise correlations among haplotype abundances. Haplotypes potentially 
392 from the same genome are expected to show positive correlations across samples, whereas a

393 negative correlation indicates that the haplotypes are from different, unique genomes. In our

394 dataset, only two of the seven haplotypes (III and V) show significantly positive correlation and

395 therefore are likely to be paralogs from the same genome. The remaining haplotypes are either

396 uncorrelated or show negative correlations (Fig. S4). Only until single-copy genetic markers

397 specific for Symbiodinium are developed will we be able to fully overcome this problem

398 (LaJeunesse \& Thornhill 2011).

399 Quasi-monotypic symbiont population in Orbicella species at the FGB

400 Even though multiple haplotypes have been detected in both O. faveolata and O. franksi,

401 they were all closely related to clade B type B1, the most prevalent Symbiodinium type in the

402 Caribbean (Baker 2003; LaJeunesse 2002; LaJeunesse et al. 2003). This result is unusual for the

403 genus Orbicella, since other assessments of Symbiodinium diversity in Orbicella spp. throughout

404 the Caribbean have shown mixed populations of Symbiodinium clades ranging from A to D

405 (Rowan \& Knowlton 1995; Rowan et al. 1997; Thornhill et al. 2006; Toller et al. 2001). A variety

406 of environmental factors have been proposed to explain Symbiodinium distributions, including

407 but not limited to depth(LaJeunesse 2002), irradiance levels (itt \& Warner 1995), latitudinal

408 location (LaJeunesse et al. 2003) and temperature (LaJeunesse et al. 2010b). The fact that

409 Orbicella species from the FGB harbor reduced symbiont diversity could be explained by the fact

410 that FGB is a marginal coral reef environment. The FGB represent the northernmost latitudinal

411 reef in the Gulf of Mexico (LaJeunesse \& Trench 2000) experiences lower thermal minima

412 relative to the rest of the Caribbean (Schmahl et al. 2008; Thornhill et al. 2008). In addition, FGB

413 is one of the deepest reefs at which Orbicella spp. are found $(>17 \mathrm{~m})$, and it has been previously

414 shown that corals from deeper environments have fewer mixed infections (LaJeunesse 2002).

415 Whether the within-clade haplotype diversity detected in this study has physiological

416 implications for host fitness remains unknown. This question could be addressed with future

417 association studies and manipulative experiments using faster evolving loci, such as

418 microsatellites, for a more complete characterization of the fine scale genetic diversity of

419 Symbiodinium (Finney et al. 2010; Pettay \& LaJeunesse 2007; Santos et al. 2004; Thornhill et al.

420 2014).

421 Symbiodinium variation between two geographic locations

422 Three minor Symbiodinium haplotypes (IV, VI and VII) represented at the level of 0.1-

$42310 \%$ of the total were significantly different in abundance between sampled locations, but not

424 between host species (Fig. 4). Previous studies of broadcast-spawning corals have shown genetic 
425 differentiation of Symbiodinium across relatively small geographic distances (Howells et al.

426 2012; Howells et al. 2009; Kirk et al. 2009). Another study also showed strong genetic

427 divergence in Symbiodinium communities and in host species across different habitat types

428 (Bongaerts et al. 2010). Still, our results are unexpected given significant genetic differentiation

429 between the host species (Fig. 2 and Table 1) and the fact that the sampled locations are in close

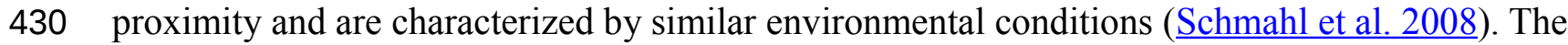

431 detected difference in Symbiodinium between east and west banks could be due to random drift in

432 isolation: 19 kilometers of deep water with no "stepping stone" habitats could present a barrier to

433 Symbiodinium dispersal, which remains a poorly understood process. Alternatively, the

434 differences could be due to subtle variation in environmental conditions. However, this latter

435 explanation requires no genetic recombination between the detected Symbiodinium haplotypes.

436 Only then would the environmental selection be likely to alter the relative frequencies of whole

437 genomes of these detected haplotypes including the ITS-2 marker. These alternatives will be

438 interesting to investigate in the future using higher-resolution genetic markers for Symbiodinium

439 (e.g. microsatellites), especially in conjunction with holobiont physiology

440 Detecting Symbiodinium community shifts

441 Two mechanisms have been proposed to explain the plasticity of symbiosis between host

442 and symbiont termed "shuffling" and "switching". "Shuffling" is a change in the existing

443 proportions of a mixed Symbiodinium infection whereby a dominant symbiont type may become

444 reduced while a background symbiont type becomes prevalent (Berkelmans \& van Oppen 2006;

445 Fay \& Weber 2012; LaJeunesse et al. 2009; Rowan et al. 1997; Silverstein et al. 2012; Stat et al.

446 2006). "Switching" is a postulated event reflecting the idea of an "open" symbiotic system when

447 a new exogenous Symbiodinium becomes the dominant type (Baker 2001; Buddemeier \& Fautin

448 1993). In order to assess whether corals "switch" or "shuffle", we must consistently and

449 confidently detect the cryptic Symbiodinium diversity. Use of a highly sensitive and quantitative

450 genotyping method will allow for the assessment of distribution patterns of Symbiodinium-host

451 relationships across spatial scales. By doing so, it will also become more feasible to examine

452 changes in Symbiodinium composition over time and detect species shuffling as well as potential

453 horizontal uptake with finer spatio-temporal resolution. The quantification methodology

454 described here and in recent publications (Kenkel et al. 2013; Quigley et al. 2014) will contribute

455 to a better understanding of the plasticity of symbiosis and community composition shifts. This

456 ITS-based Symbiodinium metabarcoding protocol utilizes primers common to all Symbiodinium

457 clades and therefore permits not only detection of known genotypes, but also discovery of new 
458

459

460

461

462

463

464

465

466

467

468

469

470

471

472

473

474

475

476

477

478

479

480

481

482

483

484

485

486

487

488

489

ones. Recent studies are also starting to apply this approach to investigate other members of the coral holobiont (․ㅐwer et al. 2002), such as other algae (Davies et al. 2014), fungi, protists (Cumbo et al. 2013), bacteria (Ceh et al. 2010; Morrow et al. 2012; Sunagawa et al. 2009), archaea (Beman et al. 2007) and viruses.

\section{MCMC.OTU package: Model-based approach to quantitative metabarcoding}

This paper provides a universal model-based statistical framework for analyzing the quantitative shifts in community composition based on counts data. The main advantage of our approach over previously developed techniques (Paulson et al. 2013; $\underline{\text { Segata et al. 2011; White et }}$ al. 2009) is the ability to directly analyze haplotype counts (rather than haplotype proportions) using an over-dispersed Poisson-lognormal model. This properly accounts for the possibility of a sparsely represented haplotype being absent due to under-sampling rather than due to any of the modeled effects. Furthermore, the method does not require data normalization since the model accounts for the effects of unequal sequence coverage (term $c_{\mathrm{k}}$ in equation [2]). The remaining residual biases are corrected by expressing the inferred OTU-specific effects relative to those for the artificial "sum-count" OTU (term $S_{i j k}$ in equation [2]). The method draws power from analyzing all OTUs within a single model, and is very versatile in terms of experimental design, allowing for any combination of fixed and random effects. This methodology has been derived from recent advancements in analysis of quantitative PCR data (Matz et al. 2013)by incorporating modifications specific for metabarcoding such as the use of "sum-count" OTU and the assumption that the data are unlikely to include technical replicates (although the method can properly handle these as well). The method is not restricted to ITS or Symbiodinium and can feasibly analyze up to about 200 OTUs on a personal computer. We hope that it will be useful for a wide range of metabarcoding studies.

\section{Conclusions}

We present a novel methodology for quantitative analysis of metabarcoding data and apply it to assess Symbiodinium diversity at the remote Flower Garden Banks. Results show coral hosts Orbicella faveolata and O. franksi harbor Symbiodinium type B1, represented by seven haplotypes. Two of these haplotypes were significantly diminished at the west FGB and one was significantly diminished at the east FGB. Future work using faster evolving loci, such as Symbiodinium-specific microsatellites, may show variations between host species or geographic locations within clade B lineages. Wider use of metabarcoding, not only with ITS-2 but with additional loci, to quantify Symbiodinium genetic diversity within multiple hosts will 
490

491

492

493

494

495

496

497

498

499

500

501

502

503

504

505

506

507

508

509

510

511

512

513

514

515

516

517

518

519

520

521

522

523

524

525

526

527

528

529

530

531

532

533

534

535

536

significantly advance our understanding of the complex dynamics of coral-Symbiodinium

symbioses.

\section{Acknowledgements}

We are grateful to personnel at the FGBNMS (E. Hickerson \& G.P. Schmahl) for permits (FGBNMS-2009-005-A2, A3), boat time and help during fieldwork. We also thank Eli Meyer for help with Orbicella sample collections. We also appreciate Michele Weber and Anke Kleuter for assistance editing and their expertise in Symbiodinium genetic diversity, Bishoy Kamel for bioinformatics support and Dr. Scott Hunicke-Smith and staff at the Genomics Sequencing and Analysis Facility at University of Texas at Austin for technical support.

\section{References}

Altschul SF, Gish W, Miller W, Myers EW, and Lipman DJ. 1990. Basic local alignment search tool. Journal of Molecular Biology 215:403-410.

Baird A, Cumbo V, Leggat W, and Rodriguez-Lanetty M. 2007. Fidelity and flexibility in coral symbioses. Marine Ecology Progress Series 347:307-309.

Baker AC. 2001. Ecosystems: Reef Corals bleach to survive change. Nature 411:765-766.

Baker AC. 2003. Flexibility and specificity in coral-algal symbiosis: Diversity, ecology, and biogeography of Symbiodinium. Annual Review of Ecology, Evolution, and Systematics 34:661-689.

Baker AC, and Romanski AM. 2007. Multiple symbiotic partnerships are common in scleractinian corals, but not in octocorals: Comment on Goulet (2006). Marine Ecology Progress Series 335:237-242.

Beman JM, Roberts KJ, Wegley L, Rohwer F, and Francis CA. 2007. Distribution and Diversity of Archaeal Ammonia Monooxygenase Genes Associated with Corals. Applied and Environmental Microbiology 73:5642-5647.

Benjamini Y, and Hochberg Y. 1995. Controlling the False Discovery Rate: A Practical and Powerful Approach to Multiple Testing. Journal of the Royal Statistical Society Series B (Methodological) 57:289-300.

Berkelmans $\mathrm{R}$, and van Oppen $\mathrm{MJH}$. 2006. The role of zooxanthellae in the thermal tolerance of corals: a 'nugget of hope' for coral reefs in an era of climate change. Proceedings of the Royal Society B: Biological Sciences 273:2305-2312.

Bongaerts P, Riginos C, Ridgway T, Sampayo EM, van Oppen MJH, Englebert N, Vermeulen F, and Hoegh-Guldberg O. 2010. Genetic Divergence across Habitats in the Widespread Coral Seriatopora hystrix and Its Associated Symbiodinium. PLoS ONE 5:e10871.

Budd AF, Fukami H, Smith ND, and Knowlton N. 2012. Taxonomic classification of the reef coral family Mussidae (Cnidaria: Anthozoa: Scleractinia). Zoological Journal of the Linnean Society 166:465-529.

Budd AF, and Pandolfi JM. 2004. Overlapping species boundaries and hybridization within the Montastraea "annularis" reef coral complex in the Pleistocene of the Bahama Islands. Paleobiology 30:396-425.

Buddemeier RW, and Fautin DG. 1993. Coral Bleaching as an Adaptive Mechanism. BioScience 43:320-326.

Cantin NE, Oppen MJH, Willis BL, Mieog JC, and Negri AP. 2009. Juvenile corals can acquire more carbon from high-performance algal symbionts. Coral Reefs 28:405-414.

Ceh J, Van Keulen M, and Bourne DG. 2010. Coral-associated bacterial communities on Ningaloo Reef, Western Australia. FEMS Microbiology Ecology 75:134-144.

Coffroth MA, and Santos SR. 2005. Genetic Diversity of Symbiotic Dinoflagellates in the Genus Symbiodinium. Protist 156:19-34. 
537

538

539

540

541

542

543

544

545

546

547

548

549

550

551

552

553

554

555

556

557

558

559

560

561

562

563

564

565

566

567

568

569

570

571

572

573

574

575

576

577

578

579

580

581

582

583

584

585

586

587

588
Cumbo VR, Baird AH, Moore RB, Negri AP, Neilan BA, Salih A, van Oppen MJH, Wang Y, and Marquis CP. 2013. Chromera velia is Endosymbiotic in Larvae of the Reef Corals Acropora digitifera and A. tenuis. Protist 164:237-244.

David M, Dzamba M, Lister D, Ilie L, and Brudno M. 2011. SHRiMP2: Sensitive yet Practical Short Read Mapping. Bioinformatics 27:1011-1012.

Davies SW, Meyer E, Guermond SM, and Matz MV. 2014. A cross-ocean comparison of responses to settlement cues in reef-building corals. PeerJ 2:e333.

Davies SW, Rahman M, Meyer E, Green EA, Buschiazzo E, Medina M, and Matz MV. 2013. Novel polymorphic microsatellite markers for population genetics of the endangered Caribbean star coral, Montastraea faveolata. Marine Biodiversity 43:167-172.

DeSalvo MK, Sunagawa S, Fisher PL, Voolstra CR, Iglesias-Prieto R, and Medina M. 2010. Coral host transcriptomic states are correlated with Symbiodinium genotypes. Molecular Ecology 19:1174-1186.

Diekmann OE, R. P. M. Bak, L. Tonk, W. T. Stam, J. L. Olsen. 2002. No habitat correlation of zooxanthellae in the coral genus Madracis on a Curaçao reef. Marine Ecology Progress Series 227: 221-232.

Douglas AE. 1998. Host benefit and the evolution of specialization in symbiosis. Heredity 81:599-603.

Earl D, and vonHoldt B. 2012. STRUCTURE HARVESTER: a website and program for visualizing STRUCTURE output and implementing the Evanno method. Conservation Genetics Resources 4:359-361.

Edgar RC. 2010. Search and clustering orders of magnitude faster than BLAST. Bioinformatics 26:2460-2461.

Evanno G, Regnaut S, and Goudet J. 2005. Detecting the number of clusters of individuals using the software STRUCTURE: a simulation study. Molecular Ecology 14:2611-2620.

Falush D, Stephens M, and Pritchard JK. 2003. Inference of Population Structure Using Multilocus Genotype Data: Linked Loci and Correlated Allele Frequencies. Genetics 164:1567-1587.

Falush D, Stephens M, and Pritchard JK. 2007. Inference of population structure using multilocus genotype data: dominant markers and null alleles. Molecular Ecology Notes 7:574-578.

Fay SA, and Weber MX. 2012. The Occurrence of Mixed Infections of Symbiodinium (Dinoflagellata) within Individual Hosts. Journal of Phycology 48:1306-1316.

Finney JC, Pettay D, Sampayo E, Warner M, Oxenford H, and LaJeunesse T. 2010. The Relative Significance of Host-Habitat, Depth, and Geography on the Ecology, Endemism, and Speciation of Coral Endosymbionts in the Genus Symbiodinium. Microbial Ecology 60:250-263.

Fitt WK, and Warner ME. 1995. Bleaching Patterns of Four Species of Caribbean Reef Corals. The Biological Bulletin 189:298-307.

Foster NL, Paris CB, Kool JT, Baums IB, Stevens JR, Sanchez JA, Bastidas C, Agudelo C, Bush P, Day O et al. . 2012. Connectivity of Caribbean coral populations: complementary insights from empirical and modelled gene flow. Molecular Ecology 21:1143-1157.

Frade PR, Bongaerts P, Winkelhagen AJS, Tonk L, and Bak RPM. 2008. In situ Photobiology of Corals over Large Depth Ranges: A Multivariate Analysis on the Roles of Environment, Host, and Algal Symbiont. Limnology and Oceanography 53:2711-2723.

Fukami H, Budd AF, Don RL, Jara J, Kersanach R, and Knowlton N. 2004. Geographic Differences in Species Boundaries among Members of the Montastraea annularis Complex Based on Molecular and Morphological Markers. Evolution 58:324-337.

Glynn PW. 1993. Coral reef bleaching: ecological perspectives. Coral Reefs 12:1-17.

Goujon M, McWilliam H, Li W, Valentin F, Squizzato S, Paern J, and Lopez R. 2010. A new bioinformatics analysis tools framework at EMBL-EBI. Nucleic Acids Research 38:W695W699. 
589

590

591

592

593

594

595

596

597

598

599

600

601

602

603

604

605

606

607

608

609

610

611

612

613

614

615

616

617

618

619

620

621

622

623

624

625

626

627

628

629

630

631

632

633

634

635

636

637

638

639

640
Gouy M, Guindon S, and Gascuel O. 2010. SeaView Version 4: A Multiplatform Graphical User Interface for Sequence Alignment and Phylogenetic Tree Building. Molecular Biology and Evolution 27:221-224.

Hadfield JD. 2010. MCMC Methods for Multi-Response Generalized Linear Mixed Models: The MCMCglmm R Package. Journal of Statistical Software 33:1-22.

Hoegh-Guldberg O. 1999. Climate change, coral bleaching and the future of the world's coral reefs. Marine and Freshwater Research 50:839-866.

Hoegh-Guldberg O, and Smith GJ. 1989. The effect of sudden changes in temperature, light and salinity on the population density and export of zooxanthellae from the reef corals Stylophora pistillata Esper and Seriatopora hystrix Dana. Journal of Experimental Marine Biology and Ecology 129:279-303.

Howells EJ, Beltran VH, Larsen NW, Bay LK, Willis BL, and van Oppen MJH. 2012. Coral thermal tolerance shaped by local adaptation of photosymbionts. Nature Climate Change 2:116-120.

Howells EJ, Oppen MJH, and Willis BL. 2009. High genetic differentiation and cross-shelf patterns of genetic diversity among Great Barrier Reef populations of Symbiodinium. Coral Reefs 28:215-225.

Hubisz MJ, Falush D, Stephens M, and Pritchard JK. 2009. Inferring weak population structure with the assistance of sample group information. Molecular Ecology Resources 9:13221332.

IUCN. 2011. IUCN Red List of Threatened Species. Version 2011.1. IUCN, Switzerland.

Jakobsson M, and Rosenberg NA. 2007. CLUMPP: a cluster matching and permutation program for dealing with label switching and multimodality in analysis of population structure. Bioinformatics 23:1801-1806.

Jones A, and Berkelmans R. 2010. Potential Costs of Acclimatization to a Warmer Climate: Growth of a Reef Coral with Heat Tolerant vs. Sensitive Symbiont Types. PLoS ONE 5:e10437.

Jones AM, Berkelmans R, van Oppen MJH, Mieog JC, and Sinclair W. 2008. A community change in the algal endosymbionts of a scleractinian coral following a natural bleaching event: field evidence of acclimatization. Proceedings of the Royal Society B: Biological Sciences 275:1359-1365.

Kaiser HF. 1960. The Application of Electronic Computers to Factor Analysis. Educational and Psychological Measurement 20:141-151.

Kenkel CD, Goodbody-Gringley G, Caillaud D, Davies SW, Bartels E, and Matz MV. 2013. Evidence for a host role in thermotolerance divergence between populations of the mustard hill coral (Porites astreoides) from different reef environments. Molecular Ecology 22:4335-4348.

Kirk N, Andras J, Harvell CD, Santos S, and Coffroth M. 2009. Population structure of Symbiodinium sp. associated with the common sea fan, Gorgonia ventalina, in the Florida Keys across distance, depth, and time. Marine Biology 156:1609-1623.

Knowlton N, and Rohwer F. 2003. Multispecies Microbial Mutualisms on Coral Reefs: The Host as a Habitat. The American Naturalist 162:S51-S62.

Koch MA, Dobeš C, and Mitchell-Olds T. 2003. Multiple Hybrid Formation in Natural Populations: Concerted Evolution of the Internal Transcribed Spacer of Nuclear Ribosomal DNA (ITS) in North American Arabis divaricarpa (Brassicaceae). Molecular Biology and Evolution 20:338-350.

Koetschan C, Förster F, Keller A, Schleicher T, Ruderisch B, Schwarz R, Müller T, Wolf M, and Schultz J. 2010. The ITS2 Database III - sequences and structures for phylogeny. Nucleic Acids Research 38:D275-279.

Koetschan C, Hackl T, Müller T, Wolf M, Förster F, and Schultz J. 2012. ITS2 database IV: Interactive taxon sampling for internal transcribed spacer 2 based phylogenies. Molecular Phylogenetics and Evolution (in press). 
641

642

643

644

645

646

647

648

649

650

651

652

653

654

655

656

657

658

659

660

661

662

663

664

665

666

667

668

669

670

671

672

673

674

675

676

677

678

679

680

681

682

683

684

685

686

687

688

689

690

691

692

LaJeunesse TC. 2002. Diversity and community structure of symbiotic dinoflagellates from Caribbean coral reefs. Marine Biology 141:387-400.

LaJeunesse TC. 2005. "Species" Radiations of Symbiotic Dinoflagellates in the Atlantic and Indo-Pacific Since the Miocene-Pliocene Transition. Molecular Biology and Evolution 22:570-581.

LaJeunesse TC, Bhagooli R, Hidaka M, deVantier L, Done T, Schmidt GW, Fitt WK, and HoeghGuldberg O. 2004. Closely related Symbiodinium spp. differ in relative dominance in coral reef host communities across environmental, latitudinal and biogeographic gradients. Marine Ecology Progress Series 284:147-161.

LaJeunesse TC, Bonilla HR, Warner ME, Wills M, Schmidt GW, and Fitt WK. 2008. Specificity and Stability in High Latitude Eastern Pacific Coral-Algal Symbioses. Limnology and Oceanography 53:719-727.

LaJeunesse TC, Loh WKW, Woesik Rv, Hoegh-Guldberg O, Schmidt GW, and Fitt WK. 2003. Low Symbiont Diversity in Southern Great Barrier Reef Corals, Relative to Those of the Caribbean. Limnology and Oceanography 48:2046-2054.

LaJeunesse TC, Parkinson JE, and Reimer JD. 2012. A genetics-based description of Symbiodinium minutum sp. nov. and S. psygmophilum sp. nov. (Dinophyceae), two dinoflagellates symbiotic with cnidaria. Journal of Phycology 48:1380-1391.

LaJeunesse TC, Pettay DT, Sampayo EM, Phongsuwan N, Brown B, Obura DO, HoeghGuldberg O, and Fitt WK. 2010b. Long-standing environmental conditions, geographic isolation and host-symbiont specificity influence the relative ecological dominance and genetic diversification of coral endosymbionts in the genus Symbiodinium. Journal of Biogeography 37:785-800.

LaJeunesse TC, Smith R, Walther M, Pinzón J, Pettay DT, McGinley M, Aschaffenburg M, Medina-Rosas P, Cupul-Magaña AL, Pérez AL et al. . 2010a. Host-symbiont recombination versus natural selection in the response of coral-dinoflagellate symbioses to environmental disturbance. Proceedings of the Royal Society B: Biological Sciences 277:2925-2934.

LaJeunesse TC, Smith RT, Finney J, and Oxenford H. 2009. Outbreak and persistence of opportunistic symbiotic dinoflagellates during the 2005 Caribbean mass coral 'bleaching' event. Proceedings of the Royal Society B: Biological Sciences 276:4139-4148.

LaJeunesse TC, and Thornhill DJ. 2011. Improved Resolution of Reef-Coral Endosymbiont (Symbiodinium) Species Diversity, Ecology, and Evolution through psbA Non-Coding Region Genotyping. PLOS ONE 6:e29013.

LaJeunesse TC, and Trench RK. 2000. Biogeography of two species of Symbiodinium (Freudenthal) inhabiting the intertidal sea anemone Anthopleura elegantissima (Brandt). The Biological Bulletin 199:126-134.

Lang JC, Lasker HR, Gladfelter EH, Hallock P, Jaap WC, Losada FJ, and Muller RG. 1992. Spatial and Temporal Variability during Periods of "Recovery" after Mass Bleaching on Western Atlantic Coral Reefs. American Zoologist 32:696-706.

Margulies M, Egholm M, Altman WE, Attiya S, Bader JS, Bemben LA, Berka J, Braverman MS, Chen Y-J, Chen Z et al. . 2005. Genome sequencing in microfabricated high-density picolitre reactors. Nature 437:376-380.

Marshall PA, and Baird AH. 2000. Bleaching of corals on the Great Barrier Reef: differential susceptibilities among taxa. Coral Reefs 19:155-163.

Matz MV, Wright RM, and Scott JG. 2013. No Control Genes Required: Bayesian Analysis of qRT-PCR Data. PLoS ONE 8:e71448.

McWilliam H, Li W, Uludag M, Squizzato S, Park YM, Buso N, Cowley AP, and Lopez R. 2013. Analysis Tool Web Services from the EMBL-EBI. Nucleic Acids Research 41:W597-600.

Mieog JC, Olsen JL, Berkelmans R, Bleuler-Martinez SA, Willis BL, and van Oppen MJH. 2009. The Roles and Interactions of Symbiont, Host and Environment in Defining Coral Fitness. PLOS ONE 4:e6364. 
693

694

695

696

697

698

699

700

701

702

703

704

705

706

707

708

709

710

711

712

713

714

715

716

717

718

719

720

721

722

723

724

725

726

727

728

729

730

731

732

733

734

735

736

737

738

739

740

741

742

743

744

745

Morrow KM, Moss AG, Chadwick NE, and Liles MR. 2012. Bacterial Associates of Two Caribbean Coral Species Reveal Species-Specific Distribution and Geographic Variability. Applied and Environmental Microbiology 78:6438-6449.

Muscatine L, and Cernichiari E. 1969. Assimilation of photosynthetic products of zooxanthellae by a reef coral. The Biological Bulletin 137:506-523.

Muscatine L, Falkowski PG, Porter JW, and Dubinsky Z. 1984. Fate of Photosynthetic Fixed Carbon in Light- and Shade-Adapted Colonies of the Symbiotic Coral Stylophora pistillata. Proceedings of the Royal Society of London Series B Biological Sciences 222:181-202.

Oksanen J, Blanchet FG, Kindt R, Legendre P, Minchin PR, O'Hara RB, Simpson GL, Solymos $\mathrm{P}$, Stevens $\mathrm{MHH}$, and Wagner H. 2013. vegan: Community Ecology Package. R package v2.0-10 ed.

Paulson JN, Stine OC, Bravo HC, and Pop M. 2013. Differential abundance analysis for microbial marker-gene surveys. Nat Meth 10:1200-1202.

Peakall R, and Smouse PE. 2012. GenAIEx 6.5: genetic analysis in Excel. Population genetic software for teaching and research—an update. Bioinformatics 28:2537-2539.

Pettay DT, and LaJeunesse TC. 2007. Microsatellites from clade B Symbiodinium spp. specialized for Caribbean corals in the genus Madracis. Molecular Ecology Notes 7:1271-1274.

Pochon X, and Gates RD. 2010. A new Symbiodinium clade (Dinophyceae) from soritid foraminifera in Hawai'i. Molecular Phylogenetics and Evolution 56:492-497.

Pochon X, Pawlowski J, Zaninetti L, and Rowan R. 2001. High genetic diversity and relative specificity among Symbiodinium-like endosymbiotic dinoflagellates in soritid foraminiferans. Marine Biology 139:1069-1078.

Pochon X, Putnam HM, Burki F, and Gates RD. 2012. Identifying and Characterizing Alternative Molecular Markers for the Symbiotic and Free-Living Dinoflagellate Genus Symbiodinium. PLoS ONE 7:e29816.

Precht W, ML R, GS B, and GP S. 2005. Establishment and initial analysis of deep reef stations (32-40m) at the East Flower Garden Bank. Dedicated Issue, Flower Garden Banks National Marine Sanctuary. Gulf of Mexico Science 21:124-127.

Pritchard JK, Stephens M, and Donnelly P. 2000. Inference of Population Structure Using Multilocus Genotype Data. Genetics 155:945-959.

Putnam HM, Stat M, Pochon X, and Gates RD. 2012. Endosymbiotic flexibility associates with environmental sensitivity in scleractinian corals. Proceedings of the Royal Society B: Biological Sciences 279:4352-4361.

Quigley KM, Davies SW, Kenkel CD, Willis BL, Matz MV, and Bay LK. 2014. Deep-Sequencing Method for Quantifying Background Abundances of Symbiodinium Types: Exploring the Rare Symbiodinium Biosphere in Reef-Building Corals. PLoS ONE 9:e94297.

R Developmental Core Team. 2013. R: A language and environment for statistical computing. $R$ Foundation for Statistical Computing.

Reynolds JM, Bruns BU, Fitt WK, and Schmidt GW. 2008. Enhanced photoprotection pathways in symbiotic dinoflagellates of shallow-water corals and other cnidarians. Proceedings of the National Academy of Sciences 105:13674-13678.

Rocke DM, and Durbin B. 2003. Approximate variance-stabilizing transformations for geneexpression microarray data. Bioinformatics 19:966-972.

Rohwer F, Seguritan V, Azam F, and Knowlton N. 2002. Diversity and distribution of coralassociated bacteria. Marine Ecology Progress Series 243:1-10.

Rosenberg NA. 2004. DISTRUCT: a program for the graphical display of population structure. Molecular Ecology Notes 4:137-138.

Rowan R, and Knowlton N. 1995. Intraspecific diversity and ecological zonation in coral-algal symbiosis. Proceedings of the National Academy of Sciences 92:2850-2853.

Rowan R, Knowlton N, Baker A, and Jara J. 1997. Landscape ecology of algal symbionts creates variation in episodes of coral bleaching. Nature 388:265-269.

PeerJ reviewing PDF | (v2014:02:1556:1:0:NEW 27 Apr 2014) 
785

786

787

788

789

790

791

792

793

794

795

796

Sampayo EM, Franceschinis L, Hoegh-Guldberg OVE, and Dove S. 2007. Niche partitioning of closely related symbiotic dinoflagellates. Molecular Ecology 16:3721-3733.

Sampayo EM, Ridgway T, Bongaerts P, and Hoegh-Guldberg O. 2008. Bleaching susceptibility and mortality of corals are determined by fine-scale differences in symbiont type. Proceedings of the National Academy of Sciences 105:10444-10449.

Santos SR, Shearer TL, Hannes AR, and Coffroth MA. 2004. Fine-scale diversity and specificity in the most prevalent lineage of symbiotic dinoflagellates (Symbiodinium, Dinophyceae) of the Caribbean. Molecular Ecology 13:459-469.

Schmahl GP, Hickerson EL, and Precht WF. 2008. Biology and Ecology of Coral Reefs and Coral Communities in the Flower Garden Banks Region, Northwestern Gulf of Mexico. In: Riegl BM, and Dodge RE, editors. Coral Reefs of the USA. Dordrecht: Springer. p 221262.

Schultz J, Maisel S, Gerlach D, Müller T, and Wolf M. 2005. A common core of secondary structure of the internal transcribed spacer 2 (ITS2) throughout the Eukaryota. RNA 11:361-364.

Schultz J, Müller T, Achtziger M, Seibel PN, Dandekar T, and Wolf M. 2006. The internal transcribed spacer 2 database--a web server for (not only) low level phylogenetic analyses. Nucleic Acids Research 34:W704-707.

Segata N, Izard J, Waldron L, Gevers D, Miropolsky L, Garrett W, and Huttenhower C. 2011. Metagenomic biomarker discovery and explanation. Genome Biology 12:R60.

Seibel P, Muller T, Dandekar T, Schultz J, and Wolf M. 2006. 4SALE - A tool for synchronous RNA sequence and secondary structure alignment and editing. BMC Bioinformatics 7:498.

Seibel P, Muller T, Dandekar T, and Wolf M. 2008. Synchronous visual analysis and editing of RNA sequence and secondary structure alignments using 4SALE. BMC Research Notes 1:91.

Selig C, Wolf M, Müller T, Dandekar T, and Schultz J. 2008. The ITS2 Database II: homology modelling RNA structure for molecular systematics. Nucleic Acids Research 36:D377380.

Sievers F, Wilm A, Dineen D, Gibson TJ, Karplus K, Li W, Lopez R, McWilliam H, Remmert M, Söding J et al. . 2011. Fast, scalable generation of high-quality protein multiple sequence alignments using Clustal Omega. Molecular Systems Biology 7:539.

Silverstein RN, Correa AMS, and Baker AC. 2012. Specificity is rarely absolute in coral-algal symbiosis: implications for coral response to climate change. Proceedings of the Royal Society B: Biological Sciences 279:2609-2618.

Stat M, Bird CE, Pochon X, Chasqui L, Chauka LJ, Concepcion GT, Logan D, Takabayashi M, Toonen RJ, and Gates RD. 2011. Variation in Symbiodinium ITS2 Sequence Assemblages among Coral Colonies. PLOS ONE 6:e15854.

Stat M, Carter D, and Hoegh-Guldberg O. 2006. The evolutionary history of Symbiodinium and scleractinian hosts-Symbiosis, diversity, and the effect of climate change. Perspectives in Plant Ecology, Evolution and Systematics 8:23-43.

Stat M, Pochon X, Cowie ROM, and Gates RD. 2009. Specificity in communities of Symbiodinium in corals from Johnston Atoll. Mar Ecol Prog Ser 386:83-96.

Sunagawa S, DeSantis TZ, Piceno YM, Brodie EL, DeSalvo MK, Voolstra CR, Weil E, Andersen GL, and Medina M. 2009. Bacterial diversity and White Plague Disease-associated community changes in the Caribbean coral Montastraea faveolata. ISME J 3:10.

Szmant AM, Weil E, Miller MW, and Colón DE. 1997. Hybridization within the species complex of the scleractinan coral Montastraea annularis. Marine Biology 129:561-572.

Thornhill D, LaJeunesse T, Kemp D, Fitt W, and Schmidt G. 2006. Multi-year, seasonal genotypic surveys of coral-algal symbioses reveal prevalent stability or post-bleaching reversion. Marine Biology 148:711-722. 
797

798

799

800

801

802

803

804

805

806

807

808

809

810

811

812

813

814

815

816

817

818

819

820

821

822

823

824

825

826

827
Thornhill DJ, Kemp DW, Bruns BU, Fitt WK, and Schmidt GW. 2008. Correspondence between cold tolerance and temperate biogeography in a western Atlantic Symbiodinium (Dinophyta) lineage. Journal of Phycology 44:1126-1135.

Thornhill DJ, Lajeunesse TC, and Santos SR. 2007. Measuring rDNA diversity in eukaryotic microbial systems: how intragenomic variation, pseudogenes, and PCR artifacts confound biodiversity estimates. Molecular Ecology 16:5326-5340.

Thornhill DJ, Lewis AM, Wham DC, and LaJeunesse TC. 2014. Host-specialist lineages dominate the adaptive radiation of reef coral endosymbionts. Evolution 68:352-367.

Toller WW, Rowan R, and Knowlton N. 2001. Zooxanthellae of the Montastraea annularis Species Complex: Patterns of Distribution of Four Taxa of Symbiodinium on Different Reefs and Across Depths. The Biological Bulletin 201:348-359.

Trench RK. 1987. Dinoflagellates in non-parasitic symbioses. In: Taylor FJR, ed. The Biology of Dinoflagellates. London: Blackwell Scientific Publications, 530-570.

Van Oppen MJH, Palstra FP, Piquet AM-T, and Miller DJ. 2001. Patterns of coral-dinoflagellate associations in Acropora: significance of local availability and physiology of Symbiodinium strains and host-symbiont selectivity. Proceedings of the Royal Society of London Series B: Biological Sciences 268:1759-1767.

Voolstra C, Schnetzer J, Peshkin L, Randall C, Szmant A, and Medina M. 2009. Effects of temperature on gene expression in embryos of the coral Montastraea faveolata. BMC Genomics 10:627.

Warner ME, Fitt WK, and Schmidt GW. 1996. The effects of elevated temperature on the photosynthetic efficiency of zooxanthellae in hospite from four different species of reef coral: a novel approach. Plant, Cell \& Environment 19:291-299.

Warner ME, LaJeunesse TC, Robison JD, and Thur RM. 2006. The Ecological Distribution and Comparative Photobiology of Symbiotic Dinoflagellates from Reef Corals in Belize: Potential Implications for Coral Bleaching. Limnology and Oceanography 51:1887-1897.

White JR, Nagarajan N, and Pop M. 2009. Statistical Methods for Detecting Differentially Abundant Features in Clinical Metagenomic Samples. PLoS Comput Biol 5:e1000352.

Wolf M, Achtziger M, Schultz J, Dandekar T, and Müller T. 2005. Homology modeling revealed more than 20,000 rRNA internal transcribed spacer 2 (ITS2) secondary structures. RNA 11:1616-1623. 


\section{Figure 1}

The study system.

A. Location of Flower Garden Banks National Marine Sanctuary, Gulf of Mexico (2754' N, $93^{\circ} 35^{\prime} \mathrm{W}$ for east Flower Garden Banks and $27^{\circ} 53^{\prime} \mathrm{N}, 93^{\circ} 49^{\prime} \mathrm{W}$ west Flower Garden Banks)

Figure Credit: USGS (http://pubs.usgs.gov/of/2003/of03-002/html/FGB_figs.htm) B. Orbicella faveolata from Panama, Photo Credit: Mónica Medina C. Orbicella franksi from Panama, Photo Credit: Mónica Medina

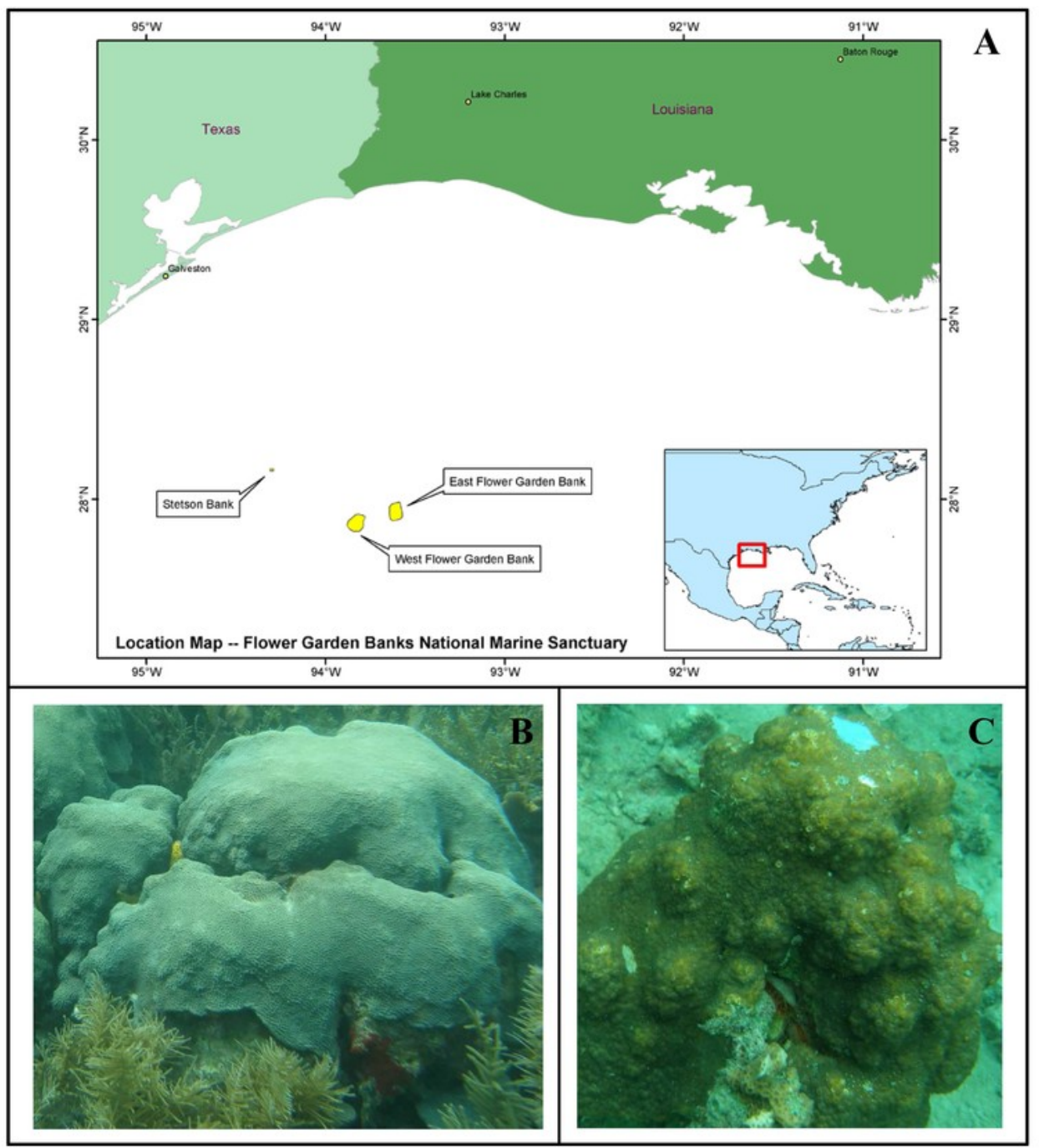




\section{Figure 2}

Genetic analysis of the coral host.

DISTRUCT plots from STRUCTURE, $\mathrm{K}=2$ except where noted A. All Orbicella faveolata and Orbicella franksi samples collected from east and west Flower Garden Banks National Marine Sanctuary, Gulf of Mexico $(n=193)$ B. Same as 'A' but potential hybrids removed $(n=174)$ C. Only Orbicella faveolata but with potential hybrids removed $(n=73, K=3)$ and $\mathbf{D}$. Only Orbicella franksi but with potential hybrids removed $(n=101)$ E. The selected 60 Orbicella faveolata $(\mathrm{n}=30)$ and Orbicella franksi $(\mathrm{n}=30)$
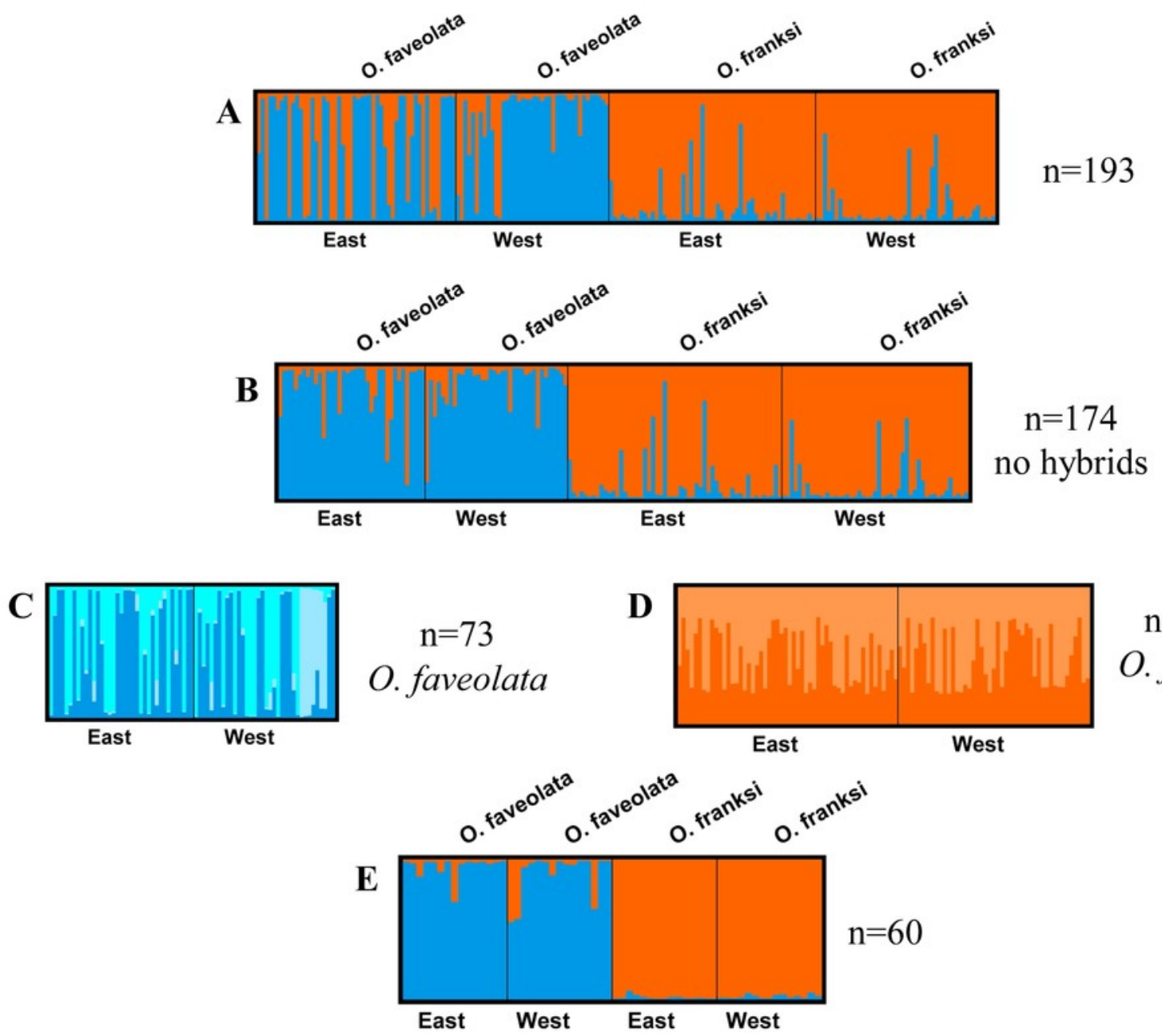


\section{Table 1 (on next page)}

Analysis of Molecular Variance (AMOVA) Fixation index $\left(F_{\mathrm{ST}}\right)$ values.

Analysis of Molecular Variance (AMOVA) Fixation index $\left(F_{\mathrm{ST}}\right)$ values showing genetic diversity results among Orbicella faveolata and Orbicella franksi, among Orbicella franksi within the two geographic locations and among Orbicella faveolata within the two geographic locations. 
$O$. faveolata vs $O$. franksi

O. franksi East vs West

$O$. faveolata East vs West

$\begin{array}{cc}\boldsymbol{F}_{\mathrm{ST}} & \boldsymbol{p} \text {-value } \\ 0.069 & 0.001 \\ 0 & 0.529 \\ 0.009 & 0.016\end{array}$




\section{Table 2 (on next page)}

The sequencing coverage and mapping efficiency by geographic location and species.

Summary of ITS-2 amplicon sequencing for two coral host species collected from Flower

Garden Banks, Gulf of Mexico using the 454 GS FLX platform. Individuals are summed by geographic location and species. 


\begin{tabular}{lcccc} 
& $\begin{array}{c}\text { Raw Read } \\
\text { Number }\end{array}$ & $\begin{array}{c}\text { Trimmed } \\
\text { Reads }\end{array}$ & $\begin{array}{c}\text { Mapped } \\
\text { Reads }\end{array}$ & $\begin{array}{c}\text { Mapping } \\
\text { Efficiency }\end{array}$ \\
\hline East & 95,478 & 68,670 & 68,637 & $100 \%$ \\
West & 74,871 & 54,197 & 54,175 & $100 \%$ \\
\hline O. faveolata & 74,840 & 53,938 & 53,913 & $100 \%$ \\
O. franksi & 95,509 & 68,929 & 68,899 & $100 \%$ \\
\hline TOTAL & 170,349 & 122,867 & 122,812 & $100 \%$
\end{tabular}




\section{Figure 3}

The percentage of reads for the seven minor Symbiodinium haplotypes by geographic location and species.

The dominant Symbiodinium B1 haplotype II comprised the remaining bulk of reads. Total read numbers were: east:Orbicella faveolata $=26,916$ reads, east:Orbicella franksi $=40,094$ reads, west:Orbicella faveolata $=26,264$ reads, west:Orbicella franksi $=27,503$ reads.

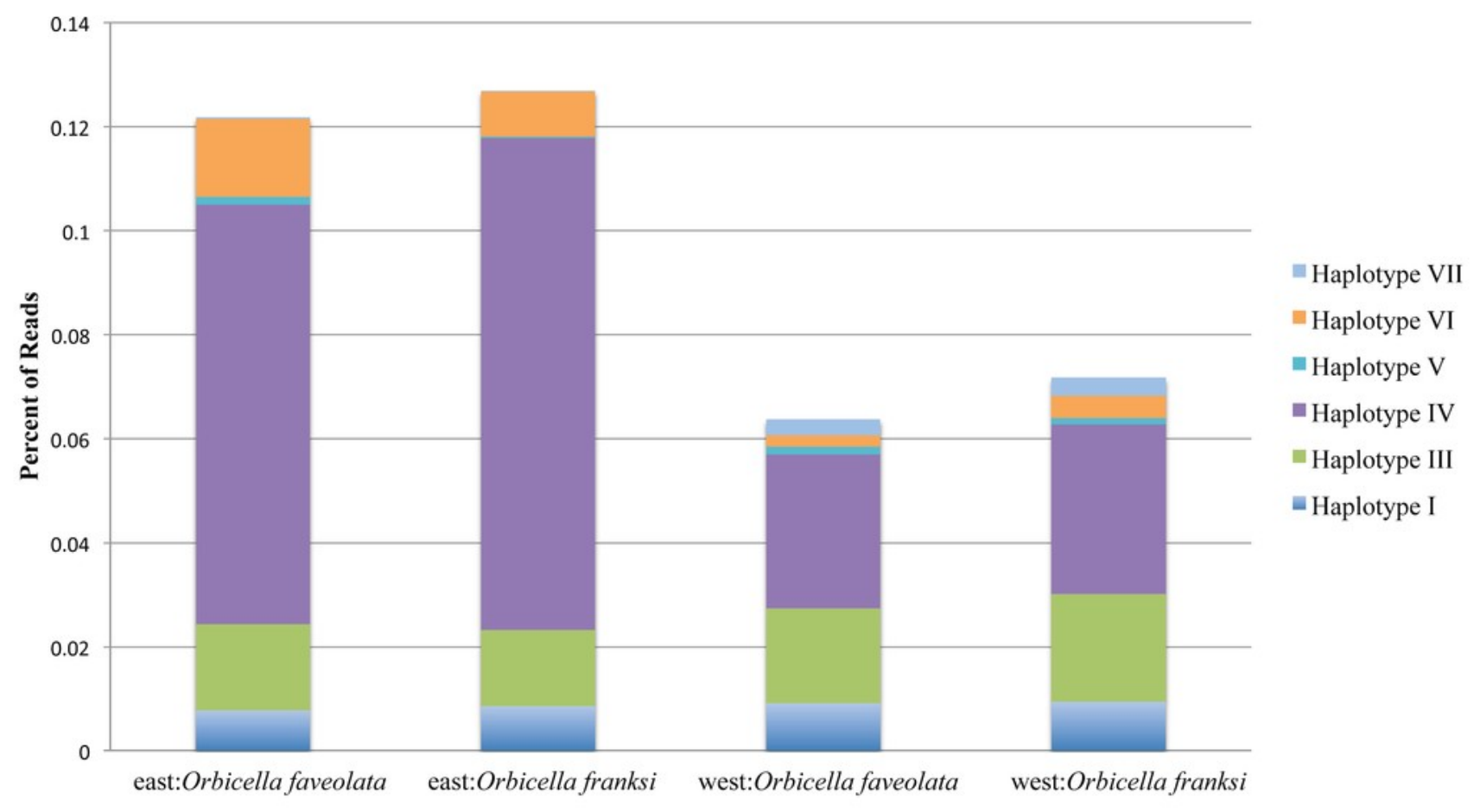




\section{Figure 4}

Distribution of abundance of the three significantly differentially represented Symbiodinium haplotypes by geographic location $(A)$ and coral species $(B)$.
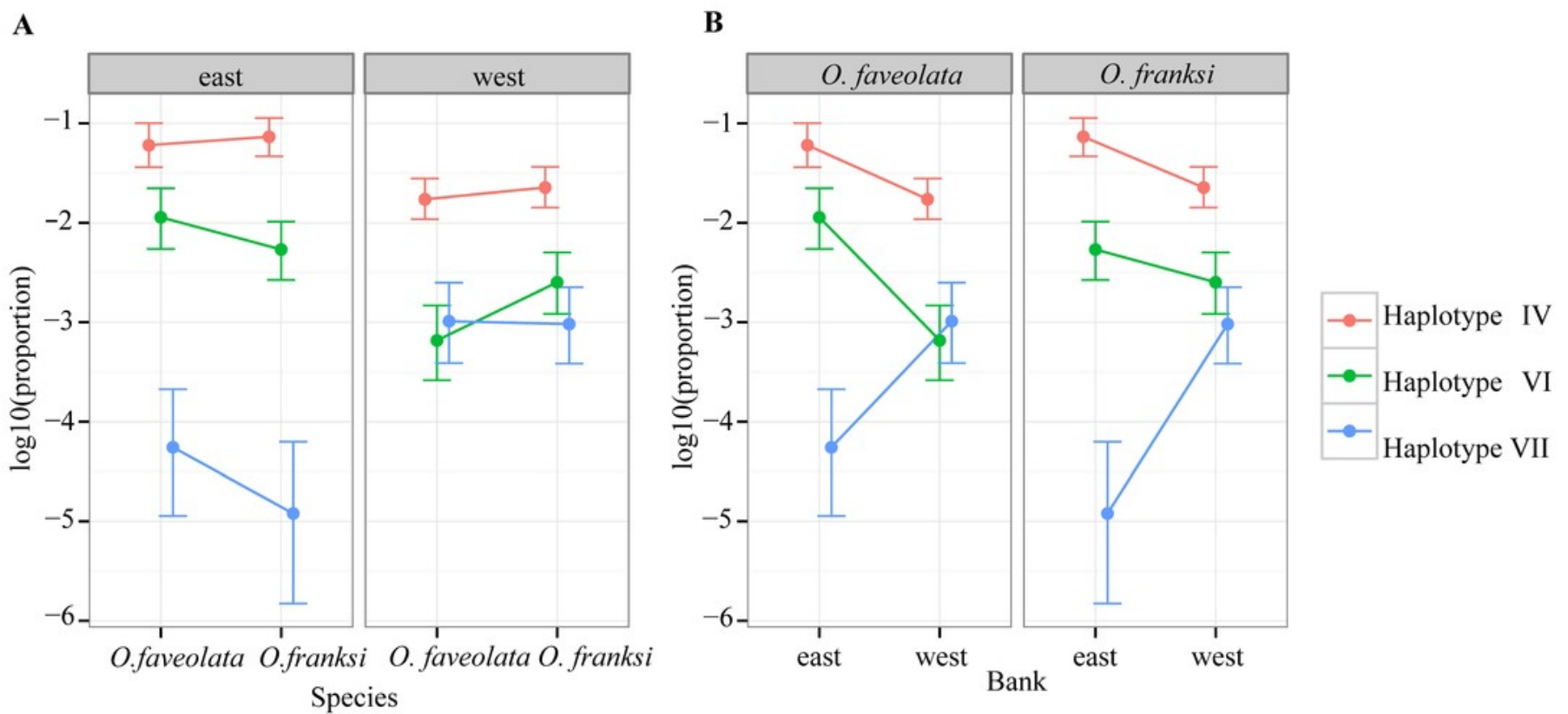


\section{Figure 5}

Principle Components Analysis (PCA) of Symbiodinium read data for all haplotypes accounting for $>0.1 \%$ of total.

First two principal components explain $30.46 \%$ of the variation $(n=57)$. Arrows are loadings for the three haplotypes significantly differentially represented between east and west banks according to the GLMM model.

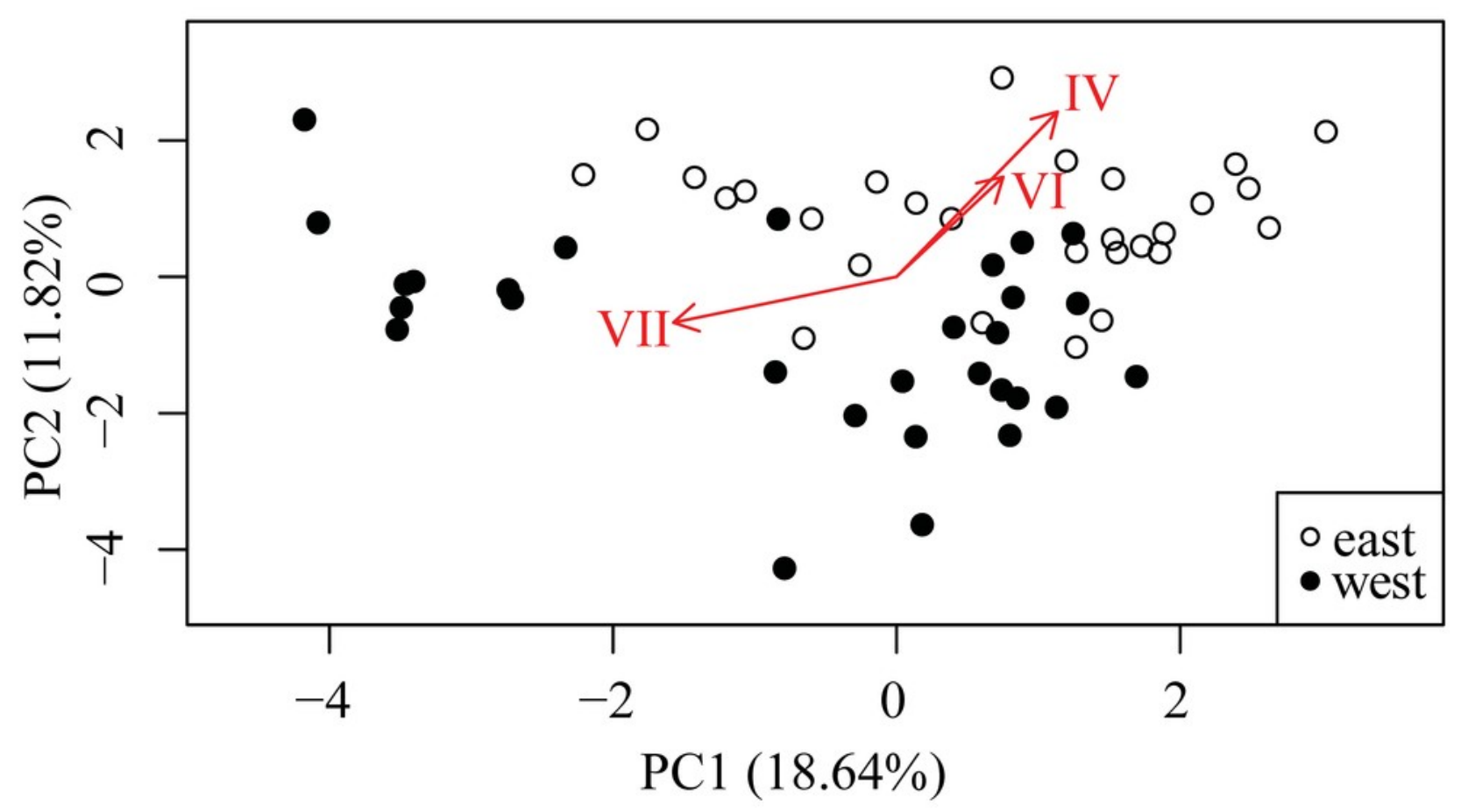

